\title{
Performing ERCP in Surgically Altered Anatomy: It Mimics Traversing a Tunnel Rather Than a Cave!
}

\author{
Shivaraj Afzalpurkar ${ }^{1}$ Mahesh Goenka ${ }^{1}$ \\ ${ }^{1}$ Institute of Gastrosciences and Liver, Apollo Gleneagles Hospital, \\ Kolkata, West Bengal, India
}

J Digest Endosc 2020;10:228-229

"Sometimes life seems a dark tunnel with no light at the end, but if you just keep moving forward, you will end up in a better place."

-Jeffrey Fry

It is always a great challenge for any endoscopist to perform an endoscopic retrograde cholangiopancreatography (ERCP) in a surgically altered gastrointestinal tract. The difficulties and challenges arise right from identifying the pancreaticobiliary enteral limb and locating the major papilla to cannulation and performing the therapeutic interventions. The possible reasons may be use of forward viewing endoscopes that lack an elevator and need of performing the procedure in relatively unstable endoscopic positions. Knowledge of postoperative reconstruction anatomy is as important as selection of appropriate endoscope types to enter the altered anatomy for successful cannulation of papilla. ERCPs in Roux-en-Y gastrojejunostomies can be successful in 33 to $67 \%$ of cases but with high complication rates. ${ }^{1,2}$ Cannulation of native papilla in a patient with Billroth II reconstruction is much more difficult due to reverse orientation of the papilla. The intubation success rate with device-assisted ERCP ranges from 40 to $100 \%{ }^{3-5}$ Sphincterotomy is also challenging due to difficult scope manoeuvrability, reverse position of papilla, and inappropriate accessories as it is difficult to keep the sphincterotomy knife in proper direction and control the size of cutting.

Several distinct techniques have been described to facilitate ERCP in surgically altered anatomy. These include the following:

1. Use of duodenoscope or forward-viewing endoscope. These are suitable only in Billroth II patients where distance between anastomosis and papilla is less than $50 \mathrm{~cm} .{ }^{6}$

2. Use of device-assisted enteroscope such as double-balloon, single-balloon or spiral enteroscope. Both double-balloon and single-balloon enteroscope are now available in small length ( $1.5 \mathrm{~m}$ compared with $2 \mathrm{~m}$ long enteroscope) to facilitate easier procedure.

3. Surgery-assisted ERCP where a gastroscopy is created surgically and a regular duodenoscope is introduced and ERCP is performed.

4. Endoscopic ultrasound (EUS)-assisted ERCP which can be antegrade by approaching the left hepatic duct through stomach and with the help of wire, approaching the bile duct. Other recently described technique is called EUS-directed transgastric ERCP (EDGE), where a lumen-apposing stent is placed at EUS between gastric pouch and excluded stomach and then papilla is approached with conventional duodenoscope. ${ }^{7}$

The study "Single-balloon enteroscopy-guided ERCP in surgically altered anatomy is safe and highly effective: results from a prospective study" by Partha Pal et $\mathrm{al}^{8}$ published in the current issue demonstrates the safety and efficacy of single-balloon enteroscopy (SBE)-ERCP in patients with altered surgical anatomy (in both Billroth II and RY anatomy) in a cohort of 28 patients undergoing 40 SBE-ERCP procedures. The endoscopic success rate in Billroth II (which includes Billroth II GJ [gastrojejunostomy] and classical Whipple's PD [pancreaticoduodenctomy]) and Roux-en-Y anatomy (RY-HJ and RY-BR in Whipple's PD) were $100 \%$ and $91.3 \%$, respectively.

In comparison to the meta-analysis by Parth Pal et $\mathrm{al}^{8}$ and Inamdar et $\mathrm{al}^{9}$ where the therapeutic success rate was of $61.7 \%$, this study has high success rate which is mainly attributed to use of long-length ERCP catheters, guidewires, and dilatation balloons which do not require exchange of SBE with conventional upper GI scope. The main drawback of this study was the small sample size. A large multicenter study using the modern ERCP accessories is needed to validate these results.

In conclusion, performing ERCP in surgically altered anatomy is a challenging endeavor. The latest technologies
Address for correspondence

Dr. Mahesh Kumar Goenka, MD, DM, Institute of Gastrosciences and Liver, Apollo Gleneagles Hospital, Day Care Building, 4th Floor, 58, Canal Circular Road, Kadapara, Phool Bagan, Kolkata, West Bengal, India (e-mail: mkgkolkata@gmail.com).
DOI https://doi.org/

10.1055/s-0040-1709647

ISSN 0976-5042.
(C)2020 Society of Gastrointestinal Endoscopy of India
License terms

(우 (1) $\Theta \circledast$ 
like short SBE with a wider (3.2 mm) working channel, oblique viewing gastroscope with an elevator, longer length of ERCP accessories, swan necked multibending backward-oblique viewing duodenoscope, and so forth have eased the job of the endoscopist in successfully performing the therapeutic pancreaticobiliary interventions in these group of patients. Many more studies are needed to evaluate the efficacy and safety of using these technologies.

\section{Conflict of Interest}

None.

\section{References}

1 Hintze RE, Adler A, Veltzke W, Abou-Rebyeh H. Endoscopic access to the papilla of Vater for endoscopic retrograde cholangiopancreatography in patients with Billroth II or Roux-en-Y gastrojejunostomy. Endoscopy 1997;29(2):69-73

2 Wright BE, Cass OW, Freeman ML. ERCP in patients with long-limb Roux-en-Y gastrojejunostomy and intact papilla. Gastrointest Endosc 2002;56(2):225-232

3 Shah RJ, Smolkin M, Yen R, et al. A multicenter, U.S. experience of single-balloon, double-balloon, and rotational overtube-assisted enteroscopy ERCP in patients with surgically altered pancreaticobiliary anatomy (with video). Gastrointest Endosc 2013;77(4):593-600
4 Katanuma A, Isayama $\mathrm{H}$. Current status of endoscopic retrograde cholangiopancreatography in patients with surgically altered anatomy in Japan: questionnaire survey and important discussion points at Endoscopic Forum Japan 2013. Dig Endosc 2014;26(Suppl 2):109-115

5 Shimatani M, Hatanaka $\mathrm{H}$, Kogure $\mathrm{H}$, et al; Japanese DB-ERC Study Group. Diagnostic and therapeutic endoscopic retrograde cholangiography using a short-type double-balloon endoscope in patients with altered gastrointestinal anatomy: a multicenter prospective study in Japan. Am J Gastroenterol 2016;111(12):1750-1758

6 Krutsri C, Kida M, Yamauchi H, Iwai T, Imaizumi H, Koizumi W. Current status of endoscopic retrograde cholangiopancreatography in patients with surgically altered anatomy. World J Gastroenterol 2019;25(26):3313-3333

7 Forster E, Elmunzer BJ. Endoscopic retrograde cholangiopancreatography in patients with Roux-en-Y gastric bypass. Am J Gastroenterol 2020;115(2):155-157

8 Pal P, Kulkarni SA, Chaudhari H, et al. Single-balloon enteroscopy-guided ERCP in surgically altered anatomy is safe and highly effective: results from a prospective study. J Digest Endosc 2020;10:221-227

9 Inamdar S, Slattery E, Sejpal DV, et al. Systematic review and meta-analysis of single-balloon enteroscopy-assisted ERCP in patients with surgically altered GI anatomy. Gastrointest Endosc 2015;82(1):9-19 